\title{
Qualidade na educação infantil em instituições brasileiras: contributos de pesquisas acadêmicas para o debate
}

Quality in early childhood education in brazilian institutions: academic research contributions to the debate

\author{
Daniele Ramos de Oliveira \\ Célia Maria Guimarães \\ Elieuza Ap. de Lima \\ Universidade Estadual Paulista "Júlio Mesquita Filho"
}

\section{Resumo}

presente artigo apresenta elementos que compõem a qualidade da educação na faixa etária de zero a cinco anos, oferecida por instituições de Educação Infantil no Brasil, com base nos resultados de pesquisa disseminados em teses e disser98 tações que enfocam essa temática. Foi utilizado o procedimento metodológico delineado como mapeamento bibliográfico das pesquisas acadêmicas brasileiras vinculadas aos Programas de Pós-Graduação em Educação, os quais focalizam a questão no período entre 1996 e 2012 . Os resultados dos estudos fornecem elementos sobre financiamento, formação de professores, família, qualidade do atendimento em redes de ensino, avaliação institucional, percepções sobre qualidade e práticas educativas que permitem discutir sobre a qualidade da Educação Infantil oferecida nas instituições brasileiras. Além disso, considera-se que não convém tomar o conceito de qualidade da Educação Infantil como universal, visto que este se vincula ao contexto, às concepções sobre criança e à sua educação.

Palavras-chave: Educação Infantil. Qualidade. Mapeamento bib́liográfico.

\section{Abstract}

This article presents elements that make up the quality of education in the age group of zero to five years, offered by institutions of Early Childhood Education in Brazil, based on research results disseminated in theses and dissertations that focus on this theme. It was used as the methodological procedure outlined mapping Brazilian literature of academic research related to the Post-Graduate Education, which focus on the issue in the period between 1996 and 2012 . The results of the study provide insights on funding, teacher training, family, quality of care in the school systems, institutional assessment, perceptions of quality and educational practices that allow discuss the quality of early childhood education offered in Brazilian institutions. Moreover, considering that not convenient to take the concept of quality of early childhood education as universal as this is linked to the context, the conceptions about children and their education.

Keywords: Early Childhood Education. Quality. Mapping literature. 


\section{Introdução}

que se busca discutir neste artigo são os elementos que compõem a qualidade da educação de zero a cinco anos, oferecida em instituições de Educação Infantil no Brasil, com base nos resultados de pesquisa disseminados em teses e dissertações que enfocam essa temática. Essa intenção tem sua justificativa na recorrente afirmação presente em nossos documentos oficiais e nas pesquisas da área: a criança tem direito à educação pública e de qualidade.

Há uma diversidade de definições para qualidade, subordinadas ao momento histórico, às ideologias, aos valores, às concepções de como a criança pensa e aprende, às afiliações políticas das pessoas, às suas tradições, aos interesses, aos papéis assumidos nas instituições, dentre outros aspectos intervenientes. A compreensão do que é qualidade varia de acordo com o contexto e suas necessidades específicas. (OLIVEIRA-FORMOZINHO, 2001 ; CRAIDY, 2002). A qualidade é um conceito relativo e dinâmico, abrangente, multidimensional, social e historicamente determinado, uma vez que emerge em uma realidade específica e num contexto concreto. (RIOS, 2001 ).

Nessa direção, Nunes e Corsino (2009) alertam sobre o que, contemporaneamente, é consensual sobre as peculiaridades do atendimento infantil, implicadas na busca da qualidade:

[...] fazer dessas instituições lugares de respeito e de valorização das crianças pequenas e suas formas de pensar, sentir e expressar-se, de convivência, de múltiplas interações e abertura para o mundo, de acesso a diferentes produções culturais, de humanização e de promoção da equidade. (NUNES; CORSINO 2009, p. 32).

Além disso, Nascimento, Campos e Coelho (201 1) complementam salientando que é indispensável ao projeto de qualidade a orientação aos profissionais da área:

Há um conhecimento maior sobre o desenvolvimento e a aprendizagem da criança pequena. Ela aprende muito com a interação entre pares, em ambientes estáveis e estimulantes; aspectos afetivos, cognitivos, físicos, sociais, culturais estão ligados; a brincadeira é a forma de expressão e criação por excelência, o vínculo com adultos é fundamental, mas não precisa ser com um só. Há orientações 
que a pedagogia deveria adotar, ao propor currículos, programas e formas de organização. Se espaços e rotinas não favorecem a brincadeira, não permitem que bebês interajam entre si e com os adultos, impedem o movimento e a expressão, não promovem a ampliação do conhecimento, então a qualidade da instituição é baixa. É urgente desenvolver traduções práticas sob esses critérios, abertos à contribuição de professores, famílias e às próprias crianças. Deixada à própria sorte, a maioria dos educadores não tem condições de fazer essa tradução. (NASCIMENTO; CAMPOS; COELHO, 201 1, p. 2031.

Nesse sentido, a necessidade de uma Educação Infantil de qualidade é consenso, porém o que se deve examinar é o significado que se atribui à qualidade, conceito este que guarda, em sua compreensão, uma multiplicidade de elementos.

De acordo com Campos, Esposito, Bhering, Gimenes e Abuchaim (201 1), a trajetória do debate sobre a qualidade da Educação Infantil seguiu rumos específicos e diversos quando comparado ao Ensino Fundamental e Médio. Nesses últimos níveis de ensino, o debate se confundiu com as disputas sobre a implantação dos sistemas centralizados de avaliação quantitativa de rendimento dos alunos, adotados em muitos países e, também, no Brasil, a partir dos anos 1990. Já na Educação Infantil, o debate sobre a qualidade foi centralizado no direito das crianças, especialmente, na busca de um atendimento que tivesse como foco principal necessidades de desenvolvimento da criança pequena. No decorrer da década de 1980, a preocupação com a qualidade se deu em torno de discussões e publicações sobre o que é qualidade, como medi-la e sobre como garanti-la. No decorrer da década de 1990, os estudos focalizavam o tema de forma indireta abordando as condições de atendimento infantil e a formação dos professores, por exemplo.

$\bigcirc$ documento "Critérios para o Atendimento em Creches que Respeitem os Direitos Fundamentais da Criança" (1995/2009) marca o início das preocupações oficiais explicitadas por meio de publicações do Ministério da Educação (MEC). O documento apresentou elementos para um atendimento de qualidade na Educação Infantil. São eles: desenvolvimento de identidade cultural, racial e religiosa, atenção individual, ambiente aconchegante, seguro e estimulante, atenção especial durante o período de adaptação à creche, proteção, afeto, amizade, direito de expressar seus sentimentos, alimentação sadia, higiene, saúde, contato com a natureza, desenvolvimento da 
curiosidade, imaginação e capacidade de expressão infantil, movimentos em espaços amplos e comprometimento com o bem-estar e desenvolvimento da criança, além do respeito aos direitos fundamentais da criança.

Vale a pena ressaltar que, nesse documento, a creche é compreendida como o atendimento para crianças de até 6 anos de idade, em tempo integral. Difere, portanto, do que preconiza a Lei de Diretrizes e Bases da Educação Nacional (LDBEN) (BRASIL, 1996), que dispõe que o atendimento em creches se destina a crianças de faixa etária de até 3 anos de idade, tanto em período integral como parcial.

Relativamente ao atendimento na Educação Infantil, o MEC propôs, em 2006, os "Parâmetros Nacionais de Qualidade" (BRASIL, 2006), nos quais o conceito de qualidade aparece assim sintetizado:

1) a qualidade é um conceito socialmente construído, sujeito a constantes negociações; 2) depende do contexto; 3) baseia-se em direitos, necessidades, demandas, conhecimentos e possibilidades; 4) a definição de critérios de qualidade está constantemente tensionada por essas diferentes perspectivas. (BRASIL, 2006, p. 24).

Nos "Referenciais Curriculares Nacionais para Educação Infantil" (BRASIL, 1998), são apontadas metas de qualidade para que as crianças tenham um desenvolvimento integral, ou seja, esse documento pode funcionar como elemento orientador de ações na busca da melhoria de qualidade da Educação Infantil brasileira, mas não tem a pretensão de resolver os complexos problemas dessa etapa educacional, conforme ressaltado:

A busca da qualidade do atendimento envolve questões amplas ligadas às políticas públicas, às decisões de ordem orçamentária, à implantação de políticas de recursos humanos, ao estabelecimento de padrões de atendimento que garantam espaço físico adequado, materiais em quantidade e qualidade suficientes e à adoção de propostas educacionais compatíveis com a faixa etária nas diferentes modalidades de atendimento, para as quais este Referencial pretende dar sua contribuição. (BRASIL, 1998, p. 11 ).

Mais tarde, em 2009, em continuidade à política de atendimento na Educação Infantil, o MEC divulga os seguintes indicadores de qualidade: 1 planejamento institucional; 2 - multiplicidade de experiências e linguagens; 
3 - interações; 4 - promoção da saúde; 5 - espaços, materiais e mobiliários;

6 - formação e condições de trabalho das professoras e demais profissionais; 7 - cooperação e troca com as famílias e participação na rede de proteção social. (BRASIL, 2009a). O objetivo foi oferecer elementos para avaliação das condições de atendimento das crianças, além de fomentar a reflexão sobre as propostas curriculares para a etapa da educação infantil.

Já as "Diretrizes Curriculares Nacionais para Educação Infantil" (BRASIL, 2009b) não apresentam especificamente indicadores de qualidade ou um conceito, mas definem, com caráter de obrigatoriedade, os princípios, fundamentos e procedimentos que orientariam os sistemas brasileiros de ensino na organização, articulação, desenvolvimento e avaliação de propostas pedagógicas destinadas às instituições de Educação Infantil. Assim sendo, destacam-se os princípios que deveriam ser respeitados, pelas instituições, no atendimento às crianças:

I - Éticos: da autonomia, da responsabilidade, da solidariedade e do respeito ao bem comum, ao meio ambiente e às diferentes culturas, identidades e singularidades.

II - Políticos: dos direitos de cidadania, do exercício da criticidade e do respeito à ordem democrática.

III - Estéticos: da sensibilidade, da criatividade, da ludicidade e da liberdade de expressão nas diferentes manifestações artísticas e culturais. (BRASIL, 2009b, p. 18).

Diante dos aspectos destacados nesses documentos, considera-se que a qualidade é um termo vinculado não só ao atendimento da criança na instituição de Educação Infantil como também à proposta pedagógica e ao currículo que orienta (ou deveria orientar) esse fazer.

A compressão sobre o que é qualidade e a definição de qual qualidade se quer para o atendimento infantil, é condição para a construção de propostas pedagógicas e curriculares com identidade própria. A clareza sobre a qualidade desejada e sobre o currículo específico da Educação Infantil subjaz à constituição da identidade desse nível de ensino, bem como da identidade do adulto a ser formado para nele atuar como professor(a). (GUIMARÃES; GARMS, 2013, p. 26). 
Por essa razão, é necessária a coerência entre a concepção de qualidade e a elaboração do currículo para a creche/pré-escola. Campos, Füllgraf e Wiggers (2006) já afiançavam, com base em resultados de pesquisa, o distanciamento entre o que está disposto em documentos oficiais e as práticas educativas encontradas nas diferentes etapas da Educação Infantil, além de destacar a precariedade observada em relação ao atendimento em creches.

Em estudo mais recente, Campos (2013) traz à baila a crescente pressão pela avaliação de resultados do atendimento infantil e aborda dilemas e desafios às políiticas públicas e programas de Educação Infantil no que diz respeito à avaliação da qualidade e do impacto desta nos anos seguintes da escolaridade. Nessa perspectiva, enfatiza que currículo e modelo pedagógico contextualizado são fundamentais para garantia dos direitos da criança.

Se, por um lado, a qualidade é um conceito relativo que deve surgir de um debate democrático e ser constantemente revisto; por outro lado, as crianças têm direito a um atendimento que respeite suas necessidades e seu protagonismo, e os aspectos mencionados devem fazer parte desse debate. A esse respeito, Oliveira, Ferreira e Barros (2011) salientam:

O desafio posto para a área não é apenas ampliar o número de crianças atendidas, [...], mas também assegurar que a educação e o cuidado dessas crianças obedeçam a determinados padrões de qualidade coletivamente estabelecidos e educacionalmente validados. (OLIVEIRA, FERREIRA; BARROS, 201 1, p. 14).

Destaca-se que, numa democracia, os objetivos mais gerais da educação não podem ser diferentes para crianças socialmente desiguais, mas é possível que os meios para alcançálos sejam diversos. Aprofundar esse questionamento pode contribuir para avanços no debate na direção de experiências educativas que contribuam para uma sociedade mais justa. (CAMPOS, 2013).

A discussão aqui proposta sobre os elementos da qualidade da Educação Infantil será desenvolvida com base nos resultados de pesquisa disseminados por estudos realizados em nível de Pós-Graduação strictu-sensu. Antes disso, porém, é necessário mencionar as estratégias metodológicas utilizadas, comportando os procedimentos de localização, seleção, síntese e sistematização dos textos que serão abordados. 


\section{Caminhos da pesquisa}

Foi desenvolvido um mapeamento bibliográfico das pesquisas acadêmicas brasileiras vinculadas aos Programas de Pós-Graduação em Educação que focalizam a questão da qualidade na Educação Infantil, publicadas entre 1996 e 2012. As dissertações de mestrado e teses de doutorado foram escolhidas como corpus do estudo, por ser a Pós-Graduação um lugar privilegiado da produção de conhecimento, em torno da qual se articulam diferentes pesquisadores para desenvolver projetos de interesse social, por um período relativamente extenso, com determinado rigor científico e aprofundamento teórico, o que pode sugerir a garantia de sua credibilidade. É possível considerar, assim, que as pesquisas acadêmicas podem auxiliar a esclarecer os elementos da qualidade na Educação Infantil, em diferentes realidades e perspectivas.

marco inicial do período escolhido para mapeamento das produções ocorreu em função da publicação da Lei de Diretrizes e Bases da Educação Nacional - LDBEN (BRASIL, 23/12/1996), que propõe a Educação Infantil como direito da criança, dever do Estado e opção da família, além de reafirmar a educação da criança de até 6 anos também como

104 direito constitucional dos pais trabalhadores. (BRASIL, 1996).

$\bigcirc$ mapeamento bibliográfico foi realizado no banco de dados da Coordenação de Aperfeiçoamento de Pessoal de Nível Superior (CAPES) e na Biblioteca Brasileira Digital de Teses e Dissertações (BDTD), com base nos seguintes descritores: "qualidade/Educação Infantil", "qualidade/creche", "qualidade/pré-escola", "avaliação/Educação Infantil"; "avaliação/ pré-escola" e "avaliação/creche". $\bigcirc$ critério de seleção principal foram os objetivos e/ou resultados dos estudos que deveriam abordar a preocupação de discutir especificamente a qualidade da Educação Infantil.

Outro critério adotado para composição da amostragem foi que os estudos estivessem disponíveis em websites e vinculados a Programas de PósGraduação em Educação. Esse último procedimento se justifica pelo fato de esses estudos poderem utilizar outros referenciais teóricos, pouco comuns na educação, o que poderia desencadear uma análise ainda mais complexa que aquela prevista para os limites deste texto.

No período entre 1996 e 2012, foram selecionadas 38 pesquisas acadêmicas que se adequavam a todos os critérios mencionados, sendo 33 
dissertações e 5 teses. A quantidade de estudos localizados a partir dos indicadores citados, porém foi bem maior, uma vez que os sistemas de busca tanto da CAPES quanto da BDTD costumam localizar todas as pesquisas que contêm, nos resumos, títulos e/ou palavras-chaves os termos utilizados. A título de exemplo, somente com o uso dos indicadores "qualidade/Educação Infantil" foram localizados na BDTD 245 documentos. Constituiu-se, portanto, em uma segunda etapa, a seleção de quais estudos comporia a amostragem e corpus do estudo, com base nos critérios já abordados para tanto. Após o processo de localização, procedeu-se à leitura dos resumos das pesquisas, cujo conteúdo possibilitou as classificações preliminares. Na sequência, foram identificados os temas abordados e os principais resultados. Alguns estudos cujo resumo não permitia compreender claramente todos os aspectos necessários para sistematização desejada foram lidos na íntegra. A partir disso, foi desenvolvida a análise que se apresenta nos próximos itens.

\section{Abordagem panorâmica das pesquisas selecionadas}

As pesquisas sobre qualidade da Educação Infantil cresceram nos últimos cinco anos, conforme é possível perceber pelos dados dispostos no Quadro 1.

\section{Quadro 1}

Distribuição de dissertações e teses publicadas de 1996 a 201 2, sobre qualidade da Educação Infantil, em Programas de Pós-Graduação em Educação, segundo o ano de publicação

\begin{tabular}{|c|c|}
\hline Ano de Publicação & $\begin{array}{c}\text { Total de } \\
\text { teses/dissertações }\end{array}$ \\
\hline 1996 & 1 \\
\hline 1997 & - \\
\hline 1998 & - \\
\hline 1999 & - \\
\hline 2000 & 1 \\
\hline 2001 & 1 \\
\hline
\end{tabular}




\begin{tabular}{|l|l|}
\hline 2002 & 1 \\
\hline 2003 & 1 \\
\hline 2004 & 2 \\
\hline 2005 & 3 \\
\hline 2006 & 3 \\
\hline 2007 & 6 \\
\hline 2008 & 3 \\
\hline 2009 & 6 \\
\hline 2010 & 2 \\
\hline 2011 & 2 \\
\hline 2012 & 6 \\
\hline
\end{tabular}

Fonte: Autoria própria

Não foram localizadas dissertações e teses sobre qualidade da Educação Infantil, no período de 1997 a 1999. É possível, contudo, considerar a hipótese de haver estudos, nesse período, não identificados por não 106 estarem disponibilizados em meio digital. $\bigcirc$ ano de 2004 marca o início de um aumento no número de estudos sobre a temática, sendo os anos de 2007 , 2009 e 2012 os mais expressivos em termos de quantidade de publicações. Esse aumento pode relacionar-se aos seguintes fatores: a contínua expansão quantitativa e qualitativa dos cursos de Pós-Graduação em Educação e dos documentos orientadores sobre a questão da qualidade nesse nível de ensino, emanados de órgãos e conselhos do Ministério da Educação, reforçado pelo acesso aos estudos e experiências estrangeiras.

A Educação Infantil constitui-se como uma etapa da Educação Básica cujo reconhecimento legal foi conquistado há pouco tempo, no Brasil. Nessa medida, a expressividade de estudos científicos, de modo geral, quando comparada àquela referente ao Ensino Fundamental, ainda é pequena. Arelaro (2005) aponta que o Ensino Fundamental público representa quase metade da produção acadêmica na área da Educação, de 1990 a 2005. 
As pesquisas acadêmicas sobre o tema têm sido produzidas em diferentes universidades, conforme sistematizado no Quadro 2. A maioria dessa produção, porém, se concentra na Universidade de Brasília, o que pode ser explicado pelo desenvolvimento dos projetos de pesquisas "Qualidade na Educação Infantil" (2001 a 2011 ) e "Visão de professores sobre a qualidade na Educação Infantil" (2010-20 1 1), vinculados a uma das linhas de pesquisa do Programa de Pós-graduação em Educação dessa universidade.

\section{Quadro 2}

Distribuição das teses e dissertações sobre qualidade da Educação Infantil, publicadas nos Programas de pós-graduação em Educação, no período de 1996 a 2012

\begin{tabular}{|c|c|}
\hline Universidades & Quantidade de teses/dissertações \\
\hline Universidade de Brasília & 18 \\
\hline Universidade Federal do Ceará & 4 \\
\hline Universidade de São Paulo & 2 \\
\hline Universidade Federal do Rio Grande do Sul & 2 \\
\hline Universidade do Vale do Itajaí & 2 \\
\hline Universidade Federal de Santa Catarina & 2 \\
\hline Universidade Federal do Paraíba & 2 \\
\hline Pontifícia Universidade Católica (Campinas, & 1 \\
\hline São Paulo) & 1 \\
\hline Universidade Estadual de Londrina & 1 \\
\hline Universidade de Campinas & 1 \\
\hline Universidade Federal do Piauí & 1 \\
\hline Universidade Católica de Santos & \\
\hline Universidade do Vale do Rio Sinos & \\
\hline
\end{tabular}

Fonte: Autoria própria

Das pesquisas acadêmicas localizadas, 55\% delas abrangem a Educação Infantil como um todo, sendo que as demais abrangem apenas uma etapa dentro desse nível de ensino: creche ou pré-escola. Destaca-se que, no caso daquelas que enfocam apenas uma das etapas da Educação Infantil, a 
maioria (32\%) se limita à pré-escola. Diversos estudos ainda utilizam creche como referência ao atendimento em tempo integral e não a idade das crianças atendidas, conforme preconiza a LDBEN. (BRASIL, 1996).

Grande parte (93\%) das pesquisas que tiveram como lócus instituições de Educação Infantil foram desenvolvidos em estabelecimentos públicos ou conveniados/subvencionados pelo poder público.

Nas pesquisas localizadas, figuram diferentes sujeitos: professores, pais, coordenadores, diretores, funcionários das escolas, técnicos de Secretaria da Educação, supervisores e crianças. A maioria das pesquisas tem o professor como principal sujeito. As crianças, embora apareçam nas pesquisas localizadas, figuram, poucas vezes, como sujeitos, uma vez que, em poucos estudos, são ouvidas. Na maioria das pesquisas, as crianças comparecem como sujeitos coletivos, com base nas observações de turmas realizadas pelos pesquisadores, com pouca ou nenhuma voz. Foram localizadas somente três pesquisas (SOUZA, 2006; JOÃO, 2007; ESCARIÃO, 2009) que envolveram a análise do ponto de vista das crianças e somente duas delas (SOUZA, 2006; ESCARIÃO, 2009) optaram por tê-las como únicos sujeitos.

Em termos de procedimentos metodológicos, as pesquisas sobre qualidade da Educação Infantil têm sido reincidentes no uso de entrevistas, observações e análises documentais. A combinação dessas três formas de coleta de dados aparece com grande frequência nas pesquisas investigadas. Mas há também pesquisas que utilizam questionários, sessões reflexivas com educadores, desenhos infantis, conversas informais, autoavaliação, vídeogravações e registros fotográficos. Ainda são poucas as pesquisas que buscam mudanças das práticas cotidianas das instituições de Educação Infantil, utilizando processos de intervenção.

Além desse quadro geral, o processo de análise dos dados obtidos possibilitou apontar algumas tendências presentes nas pesquisas. Nas seções que se seguem, serão demonstrados os múltiplos enfoques e perspectivas encontradas, distribuídos nas seguintes dimensões: financiamento, formação, família, qualidade do atendimento em redes de ensino, avaliação institucional, percepções sobre qualidade e, por fim, práticas educativas. 


\section{Tendências temáticas}

\section{1 Financiamento}

Embora as pesquisas sobre qualidade na Educação Infantil que abrangem a questão do financiamento reiterem que somente os custos não determinam as condições de qualidade, alertam que o discurso da falta de recursos pode mascarar o descomprometimento com a oferta gratuita da Educação Infantil. (BERNARDO, 2006). Nascimento (2012) destaca que, mesmo com a implementação do Fundo de Manutenção e Desenvolvimento da Educação Básica e de Valorização dos Profissionais da Educação - Fundeb, não foi possível identificar a priorização da Educação Infantil na última década. Já Ribeiro (2011) considera, com base no depoimento das coordenadoras da rede municipal de Fortaleza-CE, que o Fundeb possibilitou muitas melhorias para a Educação Infantil como aumento do número de instituições; melhoria da infraestrutura dos prédios; aumento da quantidade de profissionais; materiais e alimentação de melhor qualidade. Entretanto, os sujeitos da pesquisa reconhecem que esses avanços foram possíveis também devido a uma diversidade de fatores, dentre os quais são citados: o aumento da visibilidade da área em nível nacional, a melhoria da formação dos profissionais e a ação dos movimentos sociais em defesa do direito da criança pequena.

Segundo Nascimento (2012), o Plano Nacional de Educação (200 1 2010 ) preconizou como meta atingir, ao final da década, o atendimento para $50 \%$ das crianças de 0 a 3 anos e para $80 \%$ das crianças de 4 a 6 anos de idade, mas após o período de vigência alcançou apenas 10\% da população do primeiro grupo e 60\% das crianças em idade pré-escolar. De 2000 a 2009, enquanto o Ensino Fundamental recebeu cerca de 3,6\% do PIB, a Educação Infantil contou com 0,4\% do mesmo recurso. Diante disso, de acordo com Nascimento (2012), para atingir as metas propostas no novo Plano Nacional de Educação (Projeto de Lei no 8.035/2010) com vistas à melhoria da qualidade desse atendimento será necessário um maior investimento financeiro, principalmente por parte da União, aumentando a destinação financeira para Educação Infantil de $7 \%$ para 10\%. 


\subsection{Formação de professores}

Crepaldi (2008) e Almeida (2009) apontam que, para melhoria da qualidade na Educação Infantil, a formação de professores precisa envolver a reflexão sobre prática como ferramenta fundamental. Crepaldi (2008) sinaliza que a adoção da formação em contextos, cujo centro é a práxis, tendo como eixos de trabalho a formação, a pesquisa e a intervenção em contextos educacionais, valoriza o protagonismo da criança e do adulto.

Almeida (2009) construiu indicadores de qualidade da formação específica para formação inicial, formação em serviço e prática pedagógica docente. Referente à formação inicial, o indicador de qualidade construído foi se a formação inicial dos professores era na área de educação e em nível superior. Para formação em serviço, foram seis indicadores, a saber: 1. a formação continuada é processual e se dá, por meio de cursos de aperfeiçoamento e de formação em serviço; 2. a formação específica contempla as especificidades da educação infantil e da criança pequena; 3. na formação, é possível identificar o conhecimento do desenvolvimento infantil e a vulnerabilidade social da criança pequena; 4. a formação específica considera a 110 criança como centro de seu processo de desenvolvimento; 5. a formação específica acontece, também, por meio de uma prática refletida; 6 . a coordenação coletiva é um espaço de crescimento pessoal e profissional. Em relação à prática pedagógica, constam cinco indicadores: 1. a relação professor aluno ocorre por meio do diálogo e da mediação; 2. os aspectos emocionais da criança têm destaque no planejamento e na prática docente; 3. o professor proporciona um trabalho diversificado, incluindo o ambiente onde ocorre, e as atividades; 4. a rotina e espaços são organizados para atender às necessidades das crianças; 5. as atividades são desenvolvidas de acordo com a fase de desenvolvimento das crianças. A autora constatou que nem todos os indicadores foram amplamente contemplados no Centro de Educação Infantil pesquisado e que a discussão sobre formação na Educação Infantil ainda tem muito a ser explorada, especialmente pela falta de clareza dos profissionais para unir teoria e prática. 


\section{3 Família}

Chaves (2004) buscou identificar se a relação entre as famílias e um Jardim de Infância Público do Distrito Federal indica a complementaridade necessária para uma Educação Infantil de qualidade. A autora constatou que, embora haja uma relação de proximidade, respeito mútuo e envolvimento afetivo entre as famílias e a instituição, a relação percebida não pode ser definida como complementar, uma vez que necessitaria de alguns fatores para isso como parceria, envolvimento recíproco, corresponsabilidade e comunicação bidirecional na condução de um projeto formativo. Considera ainda que a qualidade das relações entre as famílias e as instituições constitui-se como fator imprescindível de qualidade na Educação Infantil, mas ainda como um desafio à sociedade e aos sistemas de ensino público e privado.

\subsection{Qualidade do atendimento em redes de ensino}

Aita (2005) buscou investigar qual é a qualidade do atendimento ofertado às crianças de zero a seis anos nas escolas municipais de Educação Infantil de Frederico Westphalen - Rio Grande do Sul, a partir das políticas educacionais implementadas nos anos 1990. Em seu estudo, a autora aponta que o município vem oportunizando um atendimento de qualidade, dentro de suas possibilidades, uma vez que muitas já foram as conquistas. Contudo, há ainda muito a ser reorganizado, principalmente referente a propostas pedagógicas, recursos financeiros, oferta e número adequado de instituições para atender a todas as crianças do município.

Beserra (2007) indica que, após a inserção de creches municipais de João Pessoa no sistema educacional, essas passaram a vivenciar um modelo de atendimento educacional, com perspectivas de suprimir as características assistencialistas, num processo de aprendizado de uma nova prática educativa mais ampla e com mais exigências para o atendimento de qualidade. Essa estudiosa destaca as principais mudanças percebidas após a inserção das creches nos sistemas educacionais: formação do educador, recursos materiais e existência de prática de cuidado e educação, que envolvem vivência da relação creche-família. Contudo, a autora enfatiza que urge a necessidade de implementações de ações político-administrativas em prol da ampliação da 
oferta do atendimento na Educação Infantil e da melhoria nas estruturas físicas das instituições.

Os resultados de pesquisa de Sebastiani (1996), que focaliza a qualidade da rede municipal de creches em Curitiba, durante o período de 1989 a 1992, complementam os propostos por Beserra (2007). Sebastiani (1996) alerta que é preciso se atentar para que, no ímpeto de abandonar uma visão assistencialista da creche, e de transformar esta em instituição educacional, não se caia numa preocupação unicamente "pedagógica", de modo a desconsiderar outros fatores indissociáveis da oferta de um serviço de qualidade.

Boiko (2000) investigou a qualidade do atendimento da rede municipal de Campo Mourão-Paraná. A autora indica alguns aspectos relacionados a um atendimento de qualidade, mas ressalta que a avaliação da qualidade não pode ser feita, apenas, mediante a existência ou não dos indicadores, mas sim, diante do processo de construção desses indicadores nas instituições. São eles:

[...] a organização das rotinas, a adoção de proposta pedagógica, a proporção adulto-criança no atendimento e a qualidade da interação estabelecida, a capacitação contínua dos educadores, a prática de supervisão constante, o incentivo à participação da família, a adoção de uma política que garanta a segurança das crianças, a adoção de uma políitica de saúde e a valorização das características sócio-culturais das famílias e da comunidade em todos os aspectos relacionados ao atendimento. (BOIKO, 2000, p. 8).

\subsection{Avaliação Institucional}

Duas pesquisas abordaram modelos de instrumentos de avaliação institucional para aferição da qualidade, a saber: Ciasca (2003) e Zucoloto (2011).

Ciasca (2003) analisou alguns referenciais de qualidade, previamente estabelecidos, para as instituições de Educação Infantil, apresentando um modelo de instrumento de avaliação dessa qualidade a ser usado pelos órgãos responsáveis e interessados em melhorar o atendimento das crianças de até seis anos. Esses referenciais são: estrutura física, proposta pedagógica, 
formação dos professores e formação continuada, análise das avaliações na escola (do desenvolvimento da criança, da autoavaliação do professor e da escola), comunicação com os pais e, por fim, satisfação dos participantes, professores, pais e funcionários. Após desenvolver a análise dos dados que envolveram 10 instituições de Educação Infantil, particulares e públicas, na cidade de Fortaleza-CE, concluiu que cada um desses referenciais de qualidade só será, de fato, concretizado quando interligado aos demais.

Zucoloto (2011) almejou identificar o que se entende por qualidade na educação de bebês e crianças pequenas e se a escala ITERS-R, que avalia o ambiente para crianças de até trinta meses, em instituições infantis, seria um instrumento fidedigno para a avaliação de creches. A autora evidencia que o instrumento é apropriado para avaliação de ambientes para crianças da faixa etária investigada, desde que sua implementação seja acompanhada pela formação dos profissionais que utilizariam o instrumento. Além disso, a reflexão sobre os diversos itens que compõem a escala do ambiente educativo, em um processo colaborativo entre o pesquisador e as educadoras, também pode contribuir para uma formação em contexto, que respeita a autonomia do educador para avaliar a sua prática educativa.

Numa outra perspectiva, Corrêa (2007) analisou a avaliação e a qualidade da Educação Infantil por meio de uma abordagem qualitativa dos processos avaliativos desenvolvidos na creche e na pré-escola. Concluiu que a avaliação na creche e na pré-escola apresentava as mesmas características e ambas reproduziam os moldes do Ensino Fundamental. Nesse sentido, o conceito e o desenvolvimento da avaliação na Educação Infantil ainda não se aproximam da abordagem formativa, pois se constituem como meio de controle e disciplinamento das crianças. Além disso, a autora destacou seis fatores apontados pelo corpo docente envolvido na pesquisa para uma Educação Infantil de qualidade, a saber:

a) o atendimento aos interesses e necessidades das crianças;

b) a preparação da criança para vida adulta;

c) a relação de parceria entre a família e a instituição;

d) a satisfação da criança e suas famílias;

e) a formação específica para atuar na educação infantil;

f) maior estabilidade do corpo docente na instituição no que se refere à alta rotatividades das professoras cedidas pela Secretaria de Educação. (CORRÊA, 2007, p. 204). 
Além das pesquisas citadas, três estudos (RAMPAZZO, 2009; RIBEIRO, 2010 ; BOGARIM, 2012) tiveram como foco a investigação sobre processos de avaliação institucional.

Rampazzo (2009) examinou o processo de implantação de uma experiência de avaliação institucional vivenciada por uma escola municipal de Educação Infantil, em Campinas - São Paulo. A autora ressalta que todos os segmentos precisam cooperar para a avaliação institucional e que essa se constitui como um processo que leva tempo para se concretizar, uma vez que os sujeitos envolvidos precisam negociar entre si a melhor forma de realizar essa avaliação, visando à melhoria de qualidade.

Os resultados de pesquisa de Ribeiro (2010), que buscou compreender de que forma os diferentes sujeitos (direção, coordenação pedagógica, professores, funcionários e pais) presentes em quatro creches conveniadas do município de São Paulo, contribuem para reflexões sobre o processo de construção da qualidade mediante a autoavaliação e apresentam aspectos que se articulam àqueles apresentados por Rampazzo (2009). De acordo com Ribeiro (20 10), a construção do conceito de qualidade de modo compartilhado, entre os diversos atores escolares ainda encontra empecilhos para se concretizar 114 devido, entre outros aspectos, à rígida organização hierárquica das instituições. A autora ainda destaca como as relações de poder determinam os "consensos" sobre qualidade: são negociados ou frutos do prevalecimento a ideologia de um grupo sobre os demais.

Bogarim (2012) investigou as dimensões de qualidade da Educação Infantil no contexto da Pedagogia Waldorf em uma escola particular do Distrito Federal. A qualidade da Educação Infantil foi analisada a partir de quatro indicadores construídos especialmente para o desenvolvimento do estudo: ambiente, ritmos, experiências formativas e interações/relações. "A análise das informações evidenciou a pertinência da aplicabilidade desses indicadores no contexto da Pedagogia Waldorf, bem como a relevância de considerar-se holisticamente a criança em desenvolvimento." (BOGARIM, 2012, p. 7).

\subsection{Percepções sobre Qualidade}

Stoco (200 1), Nazario (2002), Benoit (2008) e Lima (2010) trataram, em suas dissertações, das percepções de qualidade do ponto de vista 
dos professores de Educação Infantil. Para os professores de crianças de até 3 anos de uma escola do Distrito Federal, participantes do estudo de Stoco (2001), a qualidade deve ser pautada nos seguintes indicadores: aspectos emocionais da criança, organização dos espaços, relacionamento escola/ comunidade e afetividade, entendida como um fator de troca que permeia a relação entre o grupo e deste para com as crianças.

Nazario (2002) também buscou compreender os elementos considerados por um grupo de professoras para se referirem a uma boa creche. Os indicativos foram: planejamento, registro e necessidade da organização de tempos e espaços destinados às professoras, para que possam refletir sobre suas práticas cotidianas.

Já para os professores que atuam em escolas de primeira infância da rede pública de Teresina, investigados por Lima (2010), a qualidade na Educação Infantil está associada:

[...] a uma equipe de professores bem preparados; à boa estrutura física da escola, compreendida como um espaço vivo e dinâmico, que deve favorecer aventuras, descobertas, criatividade, desafios, ludicidade, confirmando as imagens da infância enquanto um tempo do brincar; ao progresso da criança, indicando que o que dá sentido à escola de Educação Infantil é, também, a aprendizagem e o desenvolvimento da criança; às questões relativas à atmosfera geral positiva da escola; à boa gestão e organização da escola e, por fim, uma escola onde se partilha a educação da criança com a família. (LIMA, 2010, p. 172).

Benoit (2008) investigou os significados de qualidade do atendimento para crianças de até seis anos expressos pelas professoras de Educação Infantil de Corupá - Santa Catarina. Tanto as professoras de creche quanto de pré-escola investigadas consideraram que a socialização representa grande benefício que os espaços de Educação Infantil podem proporcionar à criança. Enfatizam que o desenvolvimento infantil é a principal função das instituições, que devem também atender necessidades dos pais e preparar as crianças para escola. Ainda na perspectiva desses sujeitos, a Educação Infantil de qualidade deve contar com professores qualificados, sendo que a afetividade (cuidado e motivação) deve se fazer presente como aspecto inerente da qualificação profissional e um ambiente que promove oportunidades significativas de desenvolvimento. 
Basso (2004) incluiu, além dos professores, também a visão dos gestores, e Tavares (2012) optou por investigar somente a percepção dos gestores sobre qualidade na Educação Infantil. Basso (2004) utilizou alguns indicadores de qualidade, a saber: o ambiente, a gestão, a formação e desenvolvimento da equipe multidisciplinar, o currículo e o envolvimento dos pais e da comunidade. De acordo com a autora, em relação à concepção de qualidade desejada para a escola, os pontos referidos por gestores e professores foram semelhantes. Entretanto, no uso em avaliação institucional, os indicadores foram observados e avaliados de modo diferente, a depender do cargo ocupado pelo sujeito pesquisado. Para a pesquisadora, isso revela que, embora haja instrumentos e critérios para orientar uma avaliação institucional em busca de uma educação de qualidade, esses se tornam ineficazes devido à ausência de visão articulada e conjunta.

Os gestores investigados por Tavares (2012) relacionam a qualidade a espaços físicos adequados ao desenvolvimento integral das crianças, à presença de profissionais qualificados e mais bem remunerados e à participação da família na educação escolar da criança. Esses mesmos gestores destacam que os desafios para promoção da qualidade na Educação Infantil estão rela116 cionados à questão assistencialista, que ainda se faz presente nessa etapa, carência de profissionais, equipes enxutas, relação família-escola, escassez de recursos, falta de reconhecimento do poder público e falta de proximidade dos mantenedores no que se refere à gestão das entidades como instituições escolares.

Outros três estudos (SOUZA, 2006; JOÃO, 2007; ESCARIÃO, 2009) buscaram compreender a qualidade com base na percepção das crianças. João (2007) revelou os saberes, ideias e expectativas acerca de um atendimento de qualidade na Educação Infantil para pais, professores e crianças e concluiu que o conceito de qualidade é visto de forma distinta por esses diferentes grupos:

[...] para as professoras, ele passa diretamente pelos momentos de pensar e organizar as questões estruturais que são facilitadoras do processo educacional, para as famílias ele está relacionado a proteção, provisão e "educação" enquanto enquadramento social das crianças, ou seja nos resultados, esperados por eles, da educação dos seus filhos. Já para as crianças qualidade é sinônimo de prazer, prazer em aprender, em estar junto, em brincar, em comer, demonstrando pouca preocupação com a estrutura ou o resultado, mas diretamente com o processo diário vivido por elas no interior das instituições. (UО̃̃О, 2007, p. 7). 
Escarião (2009) analisou seus dados de pesquisa referentes às necessidades e expectativas das crianças com relação à escola infantil, com o propósito de melhoria da qualidade de ensino. Os resultados de sua pesquisa demonstraram que, para as crianças, a escola infantil consiste num espaço para o aprendizado e para brincadeira e que elas desejam um espaço rico em estímulos, cores e formas. A autora também destaca a importância da interação criança/criança e criança/adulto para o processo de desenvolvimento pleno e da formação dos profissionais da Educação Infantil.

Susin (2009) abordou os limites e possibilidades da qualidade da Educação Infantil comunitária conveniada no município de Porto Alegre-Rio Grande do Sul. Segundo a estudiosa, os limites e as possibilidades da qualidade da Educação Infantil comunitária estão interligados a uma história de ausência do Estado na oferta de políticas públicas para a infância e colocam em evidência a necessidade de lutas por uma educação de qualidade para todas as crianças, tendo como utopia a universalização de toda a Educação Básica.

\subsection{Práticas educativas}

Do agrupamento de pesquisas que discute as práticas educativas, quatro delas (NUNES, 2009l; SILVA, 2006; MARTINS, 2007; SIIVA, 2012) investigam as relações entre crianças e professores. Destacam-se na sequência os principais resultados.

Martins (2007) analisou os relacionamentos constituídos no trabalho pedagógico da Educação Infantil envolvendo crianças abrigadas. Os dados coletados evidenciaram posturas de disciplinamento, submissão e controle de comportamento nas relações entre adultos e crianças. De acordo com a autora, torna-se complexo discutir o sentido da qualidade a partir dos relacionamentos constituídos nessa forma de trabalho pedagógico.

Silva (2012) investiga a prática pedagógica da díade professora-monitora junto a crianças de dois anos de idade em uma creche pública do município de Barreiras-Bahia por considerar que essa forma de trabalho envolve a mediação pedagógica e, portanto, se constituiria como um indicador de qualidade na Educação Infantil. Os resultados, porém, apontam para necessidade de revisão da prática pedagógica da díade professora-monitora 
constituída na Educação Infantil, pois não há interação das ações desempenhadas por essas profissionais, o que se configura na separação dos serviços de cuidados e educação na creche. As crianças, nesse contexto, são caracterizadas como passivas nos processos de aprendizagem e desenvolvimento que Ihes são propostos e as profissionais se colocam como transmissoras ativas de conteúdos escolares, o que pouco tem relação com as necessidades educativas das crianças. Tais fatos sinalizam que a presença de duas categorias com formações e profissionalização distintas, atuando no trabalho pedagógico da creche tem comprometido a qualidade dos serviços oferecidos.

Silva (2006) buscou entender a qualidade da relação professor-aluno construída por meio do diálogo estabelecido entre professora-crianças e considerou que a qualidade dessa relação é construída no cotidiano por meio das negociações das regras de convivência e dos vínculos afetivos constituídos. Sendo assim, o diálogo pode desencadear um envolvimento afetivo sadio e propício à aprendizagem em que as decisões sobre o trabalho pedagógico são negociadas entre o grupo.

Leonília Nunes (2009) destaca que a escuta sensível de professoras pode contribuir para a construção de uma Educação Infantil de qualidade 118 quando o professor observa as representações das crianças para comunicar suas ideias com seus pares, os seus sentimentos, o seu entendimento, a sua imaginação e suas observações e utiliza desses aspectos como referência para a tomada de decisões sobre o trabalho educativo. Isso, no entanto, requer algumas características do professor como sensibilidade, espelhamento de sentimentos, empatia e diálogo.

Além dos já citados, três trabalhos (CAPISTRANO, 2005; FELIPE, 2005; MOURA, 2009) tratam de aspectos de estruturação do trabalho educativo: a organização do espaço e a brincadeira nos fazeres cotidianos.

Felipe (2005) investigou como organização do ambiente escolar se relaciona com o desenvolvimento infantil, promovendo uma Educação Infantil de qualidade. Considerou que os educadores precisam planejar a organização do ambiente escolar, de modo vinculado a uma proposta pedagógica comprometida com a qualidade na Educação Infantil, com sentido múltiplo, desafiador e organizado para a criança.

Moura (2009) destaca que a organização do espaço pode contribuir de modo significativo para uma Educação Infantil de qualidade quando proporciona à criança o direito de se tornar protagonista do seu processo de 
desenvolvimento e de aprendizagem.

Capistrano (2005) destaca que a qualidade na Educação Infantil está associada a fatores do contexto (compromisso da família, do governo e da escola), à prática do professor (atuação e formação) e à própria concepção que se tem na escola sobre Educação Infantil. A autora que teve como enfoque a brincadeira destaca que o brincar ainda não é apontado como uma das dimensões da qualidade no cotidiano escolar pelas professoras, sendo necessária uma reflexão teórico-prática para que a brincadeira possa ocupar um espaço central nos fazeres cotidianos. As professoras, sujeitos da pesquisa, apontaram que para melhoria da qualidade são necessários mais recursos, formação e compromisso de todos, inclusive mudanças em suas próprias práticas pedagógicas.

Por fim, nesse agrupamento foram incluídos mais quatro estudos (ARRUDA, 2007; SILVA, 2008; PEREIRA, 2012; SOUZA, 2012) que abordam diferentes aspectos referentes à atuação do professor: criatividade, empenhamento docente para envolver as crianças em situações de letramento, organização da prática pedagógica voltada para o contexto da escola integral e o ensino especial.

Arruda (2007) ressalta que existe relação entre a criatividade do professor no desenvolvimento do currículo e a qualidade da Educação Infantil, já que ambas têm, como perspectiva, o favorecimento da aprendizagem e desenvolvimento das crianças.

Pereira (2012) analisou a qualidade da Educação Infantil, a partir da relação entre empenhamento do professor e envolvimento da criança em situações de letramento e apontou a tendência da Educação Infantil em adotar práticas de letramento de caráter preparatório e o empenhamento do professor permeado de concepções de habilidades mecânicas relacionadas à leitura e à escrita.

Souza (2012) destaca os maiores desafios e as maiores contribuições, na visão de um grupo de professores, para a organização de uma prática pedagógica voltada para o contexto da escola de tempo integral. Como os maiores desafios para organização da prática pedagógica foram destacados: escassez de recursos humanos e materiais, desvios de função, excesso de atividades, horário entre os dois turnos, carência afetiva das crianças, apoio dos pais. Entre as maiores contribuições da prática pedagógica para uma Edu- 
cação Infantil de qualidade nas escolas de tempo integral, foram destacados os seguintes aspectos: um trabalho diversificado que reconheça o contexto social da criança ampliando as possibilidades de educar e cuidar de forma interativa; uma rotina bem estruturada com condições de ser seguida adequadamente; desenvolvimento de projetos interessantes, significativos e contextualizados que propiciem a formação integral da criança.

Rodrigues (2009) e Cruz (2007) tiveram como enfoque as rotinas. Rodrigues (2009) teve como objetivo compreender como as rotinas podem contribuir para construção da qualidade e Cruz (2007) buscou analisar as percepções das professoras, das crianças e de suas famílias acerca da rotina na pré-escola e dos fatores que presidem a sua organização, visando promover a qualidade dessa primeira etapa da Educação Básica em parceria com os profissionais que nela atuam.

Rodrigues (2009) identificou que as rotinas contribuem, significativamente, para a estruturação de uma Educação Infantil de qualidade e que os educadores têm papel fundamental nesse processo, pois são eles os responsáveis por desenvolver vínculos afetivos promotores e favorecedores da aprendizagem e do desenvolvimento da criança.

Cruz (2007), por sua vez, constatou que de todos os diferentes componentes que constituem a rotina, para as famílias e professoras, a "tarefa" é compreendida como pedagógica e essencial e a sala de aula é o espaço físico concebido como privilegiado para o desenvolvimento das atividades e para as aprendizagens das crianças. Já para as crianças, a rotina é marcada pela tarefa, que, para eles, é repetição de atividade, da qual não gostam e realiza-se na "sala da professora"; sendo que, na instituição, precisaria ter mais brincadeira. A autora considera que, para que haja renovação da rotina, em vista da construção de uma Educação Infantil de qualidade, é preciso compreender as concepções partilhadas pelos diferentes sujeitos e torná-las objeto de reflexão por todos os envolvidos na educação e no cuidado das crianças.

Resumidamente, o exposto revela que a perspectiva do que seja qualidade na Educação Infantil consiste num caminho a ser trilhado por cada instituição. Contudo, há um rumo, que se constitui com base nos documentos oficiais propostos a área nos últimos anos e nos resultados dos estudos abordados, o qual direciona para os seguintes elementos: planejamento institucional; organização dos espaços, multiplicidade de experiências e linguagens; promo- 
ção da saúde; materiais e mobiliários adequados às culturas infantis; formação e condições de trabalho para professores e demais profissionais; cooperação e troca com as famílias; respeito aos aspectos emocionais infantis; afetividade; planejamento e registro das atividades; gestão e organização escolar com compartilhamento de poder.

As pesquisas acadêmicas também abordaram os elementos que podem dificultar um atendimento de qualidade na educação infantil, a saber: falta de planejamento por parte dos professores; escassez de recursos; carência afetiva das crianças, problemas na relação família-escola e dificuldades no trabalho em equipe.

Para Angotti (2009), as condições de qualidade no atendimento da Educação Infantil são consequência de:

- mudança de cultura sobre a infância, a criança, a educação e o desenvolvimento infantil, com a divulgação mais ampla do conhecimento produzido na área;

- políticas públicas com fontes orçamentárias específicas para atender a educação infantil em suas diferentes peculiaridades de atendimento - dos 0 até os 6 anos;

- valorização dos investimentos efetivados em pesquisas, que a produção do conhecimento sobre a criança, a infância e a educação infantil, bem como sobre formação de professores não seja desconsiderada pelo poder público;

- definição legal sobre a necessária formação de professores para atuar na educação infantil, alterando o artigo 62 da LDBEN 9.394/96 para que se possa reconhecer a necessária formação na educação superior para profissionais da educação infantil e séries iniciais do ensino fundamental;

- o oferecimento do acesso e condições de permanência das crianças nas instituições de caráter educacional;

- de definição na proporção adulto/crianças nas creches e pré-escolas para um atendimento diferenciado, além de interação positiva de acoIhimento e conhecimento significativo entre os citados atores educativos. (ANGOTTI, 2009, p. 147).

É possivel depreender com isso que não há uma única qualidade e que são diversos os fatores que interferem na sua concretização. 


\section{Considerações finais}

A publicação de documentos não tem sido medida suficiente para garantia ao atendimento dos diversos critérios de qualidade nas instituições de Educação Infantil públicas, o que pode causar prejuízos ao envolvimento das crianças no contexto de um atendimento educacional institucionalizado.

Contudo, de acordo com Moss (2002, p. 23), o "[...] problema com qualidade [...]" não pode ser resolvido buscando incluir múltiplas perspectivas, pois está baseado na crença de critérios definitivos, objetivos e universais. Diante disso, o autor alerta que, em lugar de reconstruir o conceito de qualidade, se faça a opção por trabalhar com o conceito de qualidade como um meio de avaliação ou buscar outros conceitos. $\bigcirc$ autor sugere que, em lugar de se trabalhar com o conceito de qualidade, se passe a usar o conceito de criar significado (tornar significativo o que está acontecendo pelos sujeitos pertencentes a uma instituição de Educação Infantil). Para tanto, é necessário buscar formas de tornar o trabalho real desenvolvido na instituição visível e sujeito ao diálogo.

Compreender pode então levar à formação de julgamentos, que por sua vez conduz à busca de acordo, embora não necessariamente, pois o processo de aprofundar o entendimento é importante por si só. Esse exame do trabalho pedagógico deve acontecer em um contexto de debate democrático sobre uma série de questões críticas: quem nós achamos que é a criança? Quais são as finalidades das instituições para a criança pequena? Como entendemos o mundo no qual vivemos hoje? $\bigcirc$ que queremos para nossas crianças, aqui e agora e no futuro? (MOSS, 2002, p. 24).

Diante disso, a avaliação da Educação Infantil se torna conveniente ao objetivo de qualificar o atendimento institucionalizado de nossas crianças, caso os seus resultados se prestem ao que refere Campos (2013): considerar os contextos de cada realidade para a qual será proposto um modelo curricular e para a qual serão feitas opções pedagógicas. A documentação pedagógica pode ser um grande aliado nesse sentido, conforme propõe Moss (2002), pois permite assumir a responsabilidade de criar significados próprios e formas próprias de avaliação, no contexto das relações, numa prática reflexiva e democrática. 


\section{Referências}

ARELARO, Lisete Regina Gomes. $\bigcirc$ ensino fundamental no Brasil: avanços, perplexidades e tendências. Educação \& Sociedade, Campinas, v. 26, n. 92, p. 1039-1066, Trimestral (Ed. Especial), 2005.

ANGOTTI, Maristela. Os desafios da educação infantil para atingir a condição de direito e de qualidade no atendimento. In: ANGOTTI, Maristela (Org.). Educação infantil: da condição de direito à condição de qualidade no atendimento. Campinas: Alínea, 2009.

ARRUDA, Tatiana Santos. O desenvolvimento do currículo e a criatividade do professor: uma reflexão em busca da qualidade da educação infantil. 2007. 252 f. Dissertação (Mestrado em Educação) - Programa de Pós-Graduação em Educação, Universidade de Brasília, Brasília, 2007.

ALMEIDA, Fernanda Amaral. Formação profissional específica no contexto da educação infantil de qualidade. 2009. 125 f. Dissertação (Mestrado em Educação) - Programa de Pós-Graduação em Educação, Universidade de Brasília, Brasília, 2009.

AITA, Maria Cristina Gubiani. Políticas públicas e educação infantil: um olhar sobre a qualidade do atendimento ofertado às crianças nas instituições de Educação Infantil do município de Frederico Westphalen. 2005. 112 f. Dissertação (Mestrado em Educação) - Programa de Pós-Graduação em Educação, Universidade do Vale do Rio Sinos, São Leopoldo, 2005.

BASSO, Claudia de Fátima Ribeiro. Qualidade na educação infantil: a visão de professores e gestores. 2004. 251 f. Dissertação (Mestrado em Educação) - Programa de Pós-Graduação em Educação, Universidade de Brasília, Brasília, 2004.

BOGARIM, Maria Cristina da Silva Pimentel. A qualidade da educação infantil no contexto da pedagogia Waldorf: um estudo de caso. 2012.157 f. Dissertação (Mestrado em Educação) - Programa de Pós-Graduação em Educação, Universidade de Brasília, Brasília, 2012.

BRASIL. Lei n 9.394, de 20 de dezembro de 1996. Estabelece as diretrizes e bases da educação nacional. Diário Oficial [da] União, Poder Executivo, Brasília, DF, 23 dez. 1996 b. Seção 1, p. 27833

Ministério da Educação. Critérios para um atendimento em creches que respeite

os direitos fundamentais das crianças. Brasilia: MEC/ Secretaria de Educação Fundamental/ Departamento de Política da Educação Fundamental/ Coordenação Geral de Educação Infantil, 1995. 
Ministério da Educação. Referencial curricular nacional para a educação infantil Brasilia: MEC, 1998.

Ministério da Educação. Parâmetros nacionais de qualidade para a educação infantil. Brasília: MEC/Secretaria da Educação Básica/ Departamento de Políticas de Educação/Coordenação Geral da Educação Infantil, 2006.

Ministério da Educação. Critérios para um atendimento em creches que respeite os direitos fundamentais das crianças. 2. ed. Brasília: MEC/ Secretaria da Educação Básica/ Diretoria de Concepções e Orientações Curriculares para Educação Básica/ Coordenação Geral de Educação Infantil, 2009.

Ministério da Educação. Indicadores de qualidade na educação infantil. Brasília: MEC/ Secretaria de Educação Básica, 2009a.

Ministério da Educação. Resolução CEB nº 5, de 17 de dezembro de 2009: Diretrizes Curriculares Nacionais para a educação infantil. Brasília: Diário Oficial [da] União, Poder Executivo, Brasília, DF, 18 dez. 2009b. Seção 1, p. 18.

BENOIT, Jaqueline. Qualidade em educação infantil: As concepções das professoras de educação infantil de Corupá. 2008. 116 f. Dissertação (Mestrado em Educação) Programa de Pós-Graduação em Educação, Universidade do Vale do Itajaí, Itajaí, 2008.

BERNARDO, Gertrudes Angélica Vargas. Afinal de contas, é possível responder quanto custa uma educação infantil de qualidade?: uma pergunta que leva a muitas outras. 2006. 244 f. Dissertação (Mestrado em Educação) - Programa de Pós-Graduação em Educação, Universidade Federal do Rio Grande do Sul, Porto Alegre, 2006.

BESERRA, Aurília Coutinho. A inserção das creches no sistema de ensino: conquistas, perspectivas e desafios. 2007. 167 f. Dissertação (Mestrado em Educação) - Programa de Pós-Graduação em Educação, Universidade Federal da Paraíba, João Pessoa, 2007.

$\mathrm{BOIKO}$, Vanessa Alessandra Thomaz. Qualidade do atendimento à criança de zero a 6 anos na Rede Municipal de Educação Infantil de Campo Mourão - PR. 2000. 232 f. Dissertação (Mestrado em Educação) - Programa de Pós-Graduação em Educação, Universidade Estadual de Londrina, Londrina, 2000.

CAMPOS, Maria Malta; ESPOSITO, Yara Lúcia.; BHERING, Eliana; GIMENES, Nelson; ABUCHAIM, Beatriz. A qualidade da educação infantil: um estudo em seis capitais brasileiras. Cadernos de Pesquisa, São Paulo, v.41, n .142, p. 20-54, jan./abr. 2011. 
CAMPOS, Maria Malta; FÜlLGRAF, Jodete; WIGGERS, Verena. A qualidade da educação infantil brasileira: alguns resultados de pesquisa. Cadernos de Pesquisa, São Paulo, v. 36, n. 127, p. 87-128, jan./abr. 2006.

CAMPOS, Maria Malta. Entre as políticas de qualidade e a qualidade das práticas. Cadernos de Pesquisa, São Paulo, v.43, n. 148, p. 22-43, jan./abr. 2013.

CAPISTRANO, Fabiana Pereira. O brincar e a qualidade na educação infantil: concepções e prática do professor. 2005. 180 f. Dissertação (Mestrado em Educação) - Programa de Pós-Graduação em Educação, Universidade de Brasília, Brasília. 2005.

CHAVES, Laura Cristina Peixoto. Educação infantil em contexto: a relação complementar familia/instituição como fator de qualidade. 2004. 143 f. Dissertação (Mestrado em Educação) - Programa de Pós-Graduação em Educação, Universidade de Brasília, 2004.

CIASCA, Maria Isabel Filgueiras Lima. Qualidade na educação infantil: proposta de avaliação institucional em busca de novos rumos. 2003. 253 f. Tese (Doutorado em Educação) - Programa de Pós-Graduação em Educação, Universidade Federal do Ceará, Fortaleza, 2003.

CORRÊA, Maria Thereza de Oliveira. Avaliação e a qualidade da educação infantil: uma análise dos processos avaliativos desenvolvidos na creche e na pré-escola. 2007. 248 f. Dissertação (Mestrado em Educação) - Programa de Pós-Graduação em Educação, Universidade de Brasília, Brasília, 2007.

CRAIDY, Carmen Maria. A educação da criança de 0 a 6 anos: o embate assistência e educação na conjuntura nacional e internacional. In: Maria Lúcia de A. Machado (Org.). Encontros e desencontros em educação infantil. São Paulo: Cortez, 2002.

CREPALDI, Roselene. Formação em contexto: a contribuição de grupos de pesquisa para o desenvolvimento profissional na educação infantil. 2008. 222 f. Tese (Doutorado em Educação) - Programa de Pós-Graduação em Educação, Universidade Estadual de São Paulo, São Paulo, 2008.

CRUZ, Rosimeire Costa de Andrade. A rotina da pré-escola na visão das professoras, das crianças e de suas famílias. 2007. 301 f. Tese (Doutorado em Educação) - Programa de Pós-Graduação em Educação, Universidade Federal do Ceará, Fortaleza, 2007.

ESCARIÃO, Andréia Dutra. O que pensa a criança pequena sobre a escola infantile 2009. 128 f. Dissertação (Mestrado em Educação) - Programa de Pós-Graduação em Educação, Universidade Federal da Paraíba, João Pessoa, 2009. 
FELIPE, Deise Avelino. A organização do ambiente escolar e as necessidades do desenvolvimento da criança: em busca da qualidade na educação infantil. 2005. 91 f. Dissertação (Mestrado em Educação) - Programa de Pós-Graduação em Educação, Universidade de Brasília, Brasília, 2005.

GUIMARÃES, Célia Maria; GARMS, Gilza Maria Zauhy. Currículo para a educação e - cuidado da criança de 0 a 5 anos? Revista Educação - PUC - Campinas, v. 18, p. 19-35, jan./jun. 2013.

JOÃO, Janaína da Silva. Educação infantil para além do discurso da qualidade: sentidos e significações da educação infantil para pais, professores e crianças. 2007. 130 f. Dissertação (Mestrado em Educação) - Programa de Pós-Graduação em Educação, Universidade Federal de Santa Catarina, Florianópolis, 2007.

LIMA, Maria Carmem Bezerra. A qualidade em educação infantil nas representações sociais de professores da primeira infância. 2010. 187 f. Dissertação (Mestrado em Educação) Programa de Pós-Graduação em Educação, Universidade Federal do Piauí, Teresina, 2010.

MARTINS, Maria Aparecida Camarano. Os relacionamentos constituídos no trabalho pedagógico da educação infantil envolvendo crianças abrigadas: análise em busca do sentido da qualidade. 2007. 175 f. Dissertação (Mestrado em Educação) - Programa de

126 Pós-Graduação em Educação, Universidade de Brasília, Brasília, 2007.

MOSS, Peter. Para além dos problemas com qualidade. In: Machado, MACHADO, Maria Lucia A. (Org.). Encontros e desencontros em educação infantil. São Paulo: Cortez, 2002.

MOURA, Margarida Custódio. Organização do espaço: contribuições para uma educação infantil de qualidade. 2009. 121 f. Dissertação (Mestrado em Educação) - Programa de Pós-Graduação em Educação, Universidade de Brasília, Brasília, 2009.

NASCIMENTO, Maria Letícia; CAMPOS, Maria Malta; COELHO, Rita. As políticas e a gestão da Educação Infantil. Revista Retratos da escola, Brasília, v. 5, n. 9, p. 201-214, jul./dez. 2011 1. (Dosssiê-Educação Infantil). Disponível em: <http//www.esforce.org.br>. Acesso em: 10 jun. 2012.

NASCIMENTO, Ana Paula Santiago. Avanços e retrocessos na oferta da educação infantil no Brasil: análise financeiro orçamentária dos recursos destinados a essa etapa da educação 2001-2010. 2012. 228 f. Dissertação (Mestrado em Educação) - Programa de Pós-Graduação em Educação, Universidade de São Paulo, São Paulo, 2012. 
NAZARIO, Roseli. A "boa creche" do ponto de vista das professores de Educação Infantil. 2002. 116 f. Dissertação (Mestrado em Educação) - Programa de Pós-Graduação em Educação, Universidade Federal de Santa Catarina, Florianópolis, 2002.

NUNES, Leonília de Souza. Escuta sensível do professor: uma dimensão da qualidade da educação infantil. 2009. 110 f. Dissertação (Mestrado em Educação) - Programa de PósGraduação em Educação, Universidade de Brasília, Brasília, 2009l.

NUNES, Maria Fernanda Rezende; CORSINO, Patrícia. A institucionalização da infância: antigas questões e novos desafios. In: CORSINO, Patrícia (Org.). Educação infantil: cotidiano e políticas. Campinas: Autores Associados, 2009.

OLIVEIRA-FORMOZINHO, Júlia. A visão de qualidade da associação criança: contributos para uma definição. In: OLIVEIRA-FORMOZINHO, Júlia; FORMOSINHO, João (Org.) Associação criança: um contexto de formação em contexto. Braga: Livraria do Minho, 2001.

OLIVEIRA, Zilma Maria Ramos de; FERREIRA, Marisa Vasconcellos; BARROS, Joseane Ap. Bonfim. Formação continuada em educação infantil: a construção de uma agenda de possibilidades. In: GUIMARAES, Célia Maria; REIS, Pedro Guilherme Rocha Reis. Professores e infâncias: estudos e experiências. Araraquara: Junqueira \& Marin, 2011.

PEREIRA, Aline Souza. A qualidade da educação infantil no âmbito do letramento: o empenhamento do professor e o envolvimento de crianças do $2^{\circ}$ período. 2012. 102

f. Dissertação (Mestrado em Educação) - Programa de Pós-Graduação em Educação, Universidade de Brasília, Brasília, 2012.

RAMPAZZO, Vânia Cristina Tedeschi. Avaliação institucional de educação infantil: um campo de possibilidades. 2009. 122 f. Dissertação (Mestrado em Educação) - Programa de Pós-Graduação em Educação, Pontifícia Universidade Católica de Campinas, Campinas, 2009.

RIBEIRO, Bruna. A qualidade na educação infantil: uma experiência de autoavaliação em creches da cidade de São Paulo. 2010. 198 f. Dissertação (Mestrado em Educação) Programa de Pós-Graduação em Educação, Pontifícia Universidade Católica de São Paulo, São Paulo, 2010.

RIBEIRO, Maria de Jesus Araújo. Impactos iniciais do FUNDEB na qualidade da educação infantil pública no município de Fortaleza. 2011. 120 f. Dissertação Mestrado em Educação) - Programa de Pós-Graduação em Educação, Universidade Federal do Ceará, Fortaleza, 2011. 
RIOS, Terezinha Azerêdo. Compreender e ensinar: por uma docência da melhor qualidade. 2. ed. São Paulo: Cortez, 2001.

RODRIGUES, Charlene de Oliveira. A construção das rotinas: caminhos para uma educação infantil de qualidade. 2009. 137 f. Dissertação (Mestrado em Educação) - Programa de PósGraduação em Educação, Universidade de Brasília, Brasília, 2009.

SEBASTIANI, Marcia Teixeira. Educação infantil: o desafio da qualidade - um estudo da rede municipal de creches em Curitiba - 1989 a 1992. 1996. 219 f. Tese (Doutorado em Educaçãol - Programa de Pós-Graduação em Educação, Universidade Estadual de Campinas, Campinas, 1996.

SILVA, Rosemary Guilardi. O professor especialista da sala de recursos multifuncionais e a qualidade na educação infantil: uma aproximação possível. 2008. 195 f. Dissertação (Mestrado em Educação) - Programa de Pós-Graduação em Educação, Universidade de Brasília, Brasília, 2008.

SILVA, Alaídes Pereira da. Diálogo e qualidade na educação infantil: um estudo de relações na sala de aula. 2006. 98 f. Dissertação (Mestrado em Educação) - Programa de PósGraduação em Educação, Universidade de Brasília, Brasília, 2006.

128 SILVA, Lucilene Santos da. A prática pedagógica da díade de professora-monitora na perspectiva da qualidade: um estudo em creche. 2012. 156 f. Dissertação (Mestrado em Educação) - Programa de Pós-Graduação em Educação, Universidade de Brasília, Brasília, 2012.

SOUZA, Mônica Maria Silva de. Qualidade na educação infantil: o olhar da criança sobre a pré-escola. 2006. 113 f. Dissertação (Mestrado em Educação) - Programa de PósGraduação em Educação, Universidade Federal do Ceará, Fortaleza, 2006.

SOUZA, Edileia Alves Mendes de. Prática pedagógica de qualidade na educação infantil em escola de tempo integral: visão de professores. 2012. 147f. Dissertação (Mestrado em Educação) - Programa de Pós-Graduação em Educação, Universidade de Brasília, Brasília, 2012.

SUSIN, Maria Otilia Kroeff. A qualidade na educação infantil comunitária em Porto Alegre: estudo de caso em quatro creches conveniadas. 2009. 363 f. Tese (Doutorado em Educação) - Programa de Pós-Graduação em Educação, Universidade Federal do Rio Grande do Sul, Porto Alegre, 2009. 
STOCO, Rosania Aparecida. $\mathbf{0}$ a $\mathbf{3}$ anos: desafios da qualidade em educação infantil. 2001. 236 f. Dissertação (Mestrado em Educação) - Programa de Pós-Graduação em Educação, Universidade de Brasília, 2001.

TAVARES, Lucia Aparecida dos Santos. Educação infantil e terceiro setor do município de Santos: o desafio da qualidade. 2012. 140 f. Dissertação (Mestrado em Educação) - Programa de Pós-Graduação em Educação, Universidade Católica de Santos, Santos, 2012.

ZUCOLOTO, Karla Aparecida. Educação infantil em creches - uma experiência com a escala ITERS-R. 201 1. 308 f. Tese (Doutorado em Educação) - Programa de Pós-Graduação em Educação, Universidade de São Paulo, São Paulo, São Paulo, 2011.

Ms. Daniele Ramos de Oliveira Universidade Estadual Paulista "Júlio Mesquita Filho" | UNESP Faculdade de Ciências e Tecnologia, Campus de Presidente Prudente Grupo de Pesquisa Profissão Docente: formação, identidade e representações sociais E-mail | unespdaniele@gmail.com

Profa. Dra. Célia Maria Guimarães

Universidade Estadual Paulista "Júlio Mesquita Filho" | UNESP Faculdade de Ciências e Tecnologia, Campus de Presidente Prudente Programa de Pós-Graduação em Educação Líder do Grupo de Pesquisa Profissão Docente: formação, identidade e representações sociais E-mail | cmgui@fct.unesp.br 
Profa. Dra. Elieuza Ap. de Lima Universidade Estadual Paulista "Júlio Mesquita Filho" | UNESP Faculdade de Filosofia e Ciências, Campus de Marília Programa de Pós-Graduação em Educação Grupos de Pesquisa: "Implicações Pedagógicas da Teoria HistóricoCultural" e "GP FORME: Formação do Educador" e "Grupo de Pesquisa e Estudos em Educação Infantil E-mail | aelislima@ig.com.br

Recebido 11 set. 2013 Aceito 5 nov. 2013 